Religiosity or ideology? On the individual differences predictors of sexism

Word count: 6601

Running head: The role of religiosity and social attitudes in sexism 


\begin{abstract}
The present set of studies investigated the role of both religiosity and socialideological attitudes in the prediction of various forms of sexist and gender-related attitudes. Hierarchical regression analyses on data collected in three countries (i.e., two heterogeneous adult samples from Turkey and the Netherlands, and two student samples from Belgium; combined $N=964$ ) revealed that although individual differences in religiosity did predict traditional gender role beliefs and sexism (towards both women and men), its impact was limited compared to the impact of individual differences in social-ideological attitudes (i.e., social dominance orientation and particularly authoritarianism). In the discussion, we argue that sexism primarily relates to individual differences in peoples' perspective on the social world, and that religiosity explains little additional variance.
\end{abstract}

Key words: religiosity; social-ideological attitudes; sexist attitudes; traditional gender role beliefs 


\section{Religiosity or ideology? On the individual differences predictors of sexism}

It has been claimed that, to a certain extent, all the world's major religions promote gender hierarchy (e.g., Seguino 2011). For instance, the media has more than often represented Muslims as "supporters of a monolithic, homogenized, sexist religion [...] that encompasses negative attitudes and values about women as a group" (Ahmed \& Matthes, 2017, p. 4). But Christianity and Judaism, too, have been blamed for shaping traditional cultural images that degrade, and subjugate women (Ruether, 1998).

Religions provide a divinely mandated frame of reference for understanding and interpreting the world, and most religious convictions lean on holy books and traditions to justify fairly rigid gender roles and attitudes, as ordained by a God or another higher entity (Glick, Lameiras, \& Castro, 2002). As such, it seems warranted to take into account religiosity - the role religion plays in an individual's life, along with the centrality of and engagement in religious practices - when investigating sexism and gender-related attitudes. For example, recent research found that religious fundamentalism and extrinsic religious orientation predict higher negative attitudes towards gay men and lesbian women (Study 1; Anderson \& Koc, 2015). However, the same study also showed that the predictive power of these indicators of religiosity decreased when other individual differences (e.g., right-wing authoritarianism) were taken into account (Study 2; Anderson \& Koc, 2015). Accordingly, the question that arises here is: how does religiosity compare to more general socio-ideological individual differences when it comes to predicting a variety of sexist and gender-related attitudes?

\section{Individual Differences Underlying Sexism}

Glick and Fiske $(1996,1999)$ define sexism as reflecting a deep ambivalence rather than a uniform antipathy towards women (or men). This ambivalent sexism has been an 
important and popular topic in social psychology because it covers both negative and (seemingly) positive attitudes. Indeed, sexist attitudes may be organized along two complementary dimensions. The first dimension reflects hostile sexism, which entails strong feelings of antipathy or negativity. Individuals adhering to such aggressive sexist attitudes tend to perceive individuals from the other gender as competing over power and dominance. The second dimension, termed benevolent sexism, is somewhat more positive in tone and stereotypically categorizes members of a certain sex in their respective restricted roles. Individuals embracing benevolent sexist attitudes typically portray women as pure and warm but also as weak, fragile and in need for protection (Glick et al., 2000). They are motivated to justify traditional gender hierarchy by positively evaluating women in traditional gender roles. Both forms of sexism have repeatedly been linked to higher levels of religiosity among Christians (e.g., Allport \& Ross, 1967; Glick et al., 2002; Hellmer, Stenson, \& Jylhä, 2018). Also among Jews in Israel (e.g., Gaunt, 2012) and Muslims in Turkey (e.g., Taşdemir \& Sakall1-Uğurlu, 2010), religiosity has been associated with greater sexism. These studies specifically found that religiosity was a stronger predictor of benevolent sexism compared to hostile forms sexism in predominantly Christian and Muslim countries (see also Mikołajczak \& Pietrzak, 2014).

According to Duckitt (2001), however, individual differences in various forms of prejudice are better explained by two related but independent social-ideological attitude dimensions. These social-ideological attitude dimensions are often captured by Right-Wing Authoritarianism (RWA; Altemeyer, 1981) and Social Dominance Orientation (SDO; Pratto, Sidanius, Stallworth \& Malle, 1994). High levels of RWA reflect cultural conservatism and traditionalism based on a profound desire for social cohesion and collective security. High levels of SDO are an expression of economic-hierarchical conservatism, based on the motivational goal for group-based power, dominance and superiority. Together, RWA and 
SDO cast a wide-ranging net that predicts variation in most domains of prejudice, discrimination, and related intergroup attitudes (Sibley, Robertson, \& Wilson, 2006; Sibley, Wilson, \& Duckitt, 2007; Van Assche, Roets, De keersmaecker, \& Van Hiel, 2017).

Indeed, previous studies indicated that both dimensions are positively related to sexist attitudes (with RWA showing stronger associations with benevolent and SDO with hostile sexism; see Begany \& Milburn, 2002; Christopher \& Mull, 2006; Sibley et al., 2007). These findings provide a strong case for the role of social attitudes in explaining individual differences in sexism. Surprisingly, studies that have provided insight in the unique and relative contributions of authoritarianism, social dominance orientation, and religiosity in explaining sexist and gender-related attitudes, are rare (for a notable exception, see Hellmer et al., 2018). As RWA, and to a lesser extent SDO, show substantial relationships with religiosity (Altemeyer, 1981; see also Duriez \& Van Hiel, 2002), it seems especially useful to test their unique contribution in a unified design. The present set of studies aims to fill this gap in the literature. Specifically, following the Dual Process Model (Duckitt, 2001), we hypothesize that some of the 'active ingredients' of religiosity's connection with sexism pertain to traditional norms, values, and hierarchical preferences, which refer to the core aspects of RWA and SDO, rather than being defining features of religiosity an sich. As such, when these social-ideological dimensions are taken into account, the unique contribution of religiosity in explaining sexism should be curbed considerably.

\section{The Present Studies}

This research aimed to assess the relative contribution of social-ideological attitudes (i.e., RWA and SDO), compared to religiosity, in explaining individual differences in sexist attitudes and traditional gender role beliefs. To investigate this question, we recruited four samples, focusing on a wide range of sexism and gender-related attitudes. In a first study 
(conducted among Belgian students), we simultaneously focused on religiosity and socialideological attitudes in the prediction of various forms of sexism. In a second study, we also focused on traditional gender role beliefs, collecting two heterogeneous adult samples and one sample of undergraduate students. These samples stem from three different countries, where either Islam (i.e., in Turkey) or Christianity (i.e., Protestantism/Catholicism in the Netherlands and Catholicism in Belgium) is the predominant religion. It is vital to investigate the robustness of these relations across religions and cultures.

Given that various socio-demographic variables have been shown to play a role in shaping gender-related attitudes and in particular sexist attitudes, we control for these variables in our analyses. Gender differences in ambivalent sexism towards women (with men scoring higher than women) have been documented in many different national and cultural contexts (Glick et al., 2004). Besides gender, age may have an effect on the endorsement of sexist attitudes as well. Indeed, several studies have highlighted a slight increase in sexism among older individuals (e.g., Fitzpatrick Bettencourt et al., 2011). Furthermore, a higher education level has been shown to relate negatively to sexist attitudes (Glick et al., 2002). Presumably, education helps to promote more liberal gender attitudes (see also Van Hiel et al., 2018). Finally, in Study 2, we also control for income level as an indicator of greater socio-economic status (see also Begany \& Milburn, 2002).

\section{Study 1}

\section{Method}

\section{Participants}

First-year undergraduate students from a Belgian university were invited to the lab to participate in this survey in return for partial course credit $\left(N=227 ; M_{\mathrm{age}}=19,26, S D_{\text {age }}=\right.$ 3.80, with 77,5\% women). All respondents completed the full study, yielding no missing data. 


\section{Measures}

All scales were administered on 7-point Likert scales anchored by 1 ("Totally disagree") to 7 ("Totally agree").

Religiosity. Religiosity was assessed with five statements (based on Fleischmann, 2010). A sample item is "My religious and spiritual beliefs are very important in my daily life". Cronbach's alpha was .87.

Authoritarianism. Participants responded to an 11-item version of Altemeyer's (1981) RWA-scale (translated by Meloen, 1991; see also Van Assche, Bostyn, De keersmaecker, Dardenne, \& Hansenne, 2017). An example item is: "Obedience and respect for authority are the most important virtues children should learn" (with $\alpha=.81, M=3.41, S D$ $=0.9)$.

Social Dominance Orientation. The 14-item version of the SDO- scale was measured (Pratto et al., 1994). An example item is: "Some groups of people are simply inferior to other groups". Cronbach's alpha was .89 .

Sexist attitudes. Three scales tapped into sexist attitudes. Firstly, the 8-item Modern Sexism Scale (Swim, Aikin, Hall, \& Hunter, 1995) was assessed. Modern sexism is characterized by the denial of continued discrimination of women, antagonism toward women's demands, and resentment about affirmative action policies designed to help women (e.g., in education and work). An example item of such subtle and covert sexist attitudes reads "It is rare to see women treated in a sexist manner on television". Cronbach's alpha was .80.

Secondly, respondents completed the Glick and Fiske's (1996) 22-item Ambivalent Sexism Inventory (with $\alpha=.88, M=3.49, S D=0.80$ ) to measure sexism towards women. This measure gauges two components of sexist attitudes, namely hostile (e.g., "Most women 
interpret innocent remarks or actions as sexist") and benevolent (e.g., "Women should be cherished and protected by men") sexism. Cronbach's alpha was .84 and .83 for the hostile and the benevolent sexism-subscales, respectively.

Thirdly, to assess (hostile and ambivalent forms of) sexism towards men, we administered the Ambivalence toward Men Inventory (Glick \& Fiske, 1999). Cronbach's alpha was .87 and .89 for the hostile and the benevolent sexism-subscales, respectively.

\section{Results}

The means, standard deviations, and correlations among all study variables are portrayed in Table 1. Religiosity, RWA, SDO, and sexist attitudes were all positively interrelated. There was only one exception: modern sexism was unrelated to hostile sexism towards men.

\section{Table 1}

Correlations among study variables in Study 1.

\begin{tabular}{llllllllll}
\hline Measure & M & SD & 1 & 2 & 3 & 4 & 5 & 6 & 7
\end{tabular}

1. Religiosity $\quad 1.92 \quad 1.29 \quad-$

2. RWA $3.41 \quad 0.91 \quad .25^{*}$

3. SDO $2.87 \quad 0.98 \quad .15$

4. MODSEX $\quad 3.61 \quad 0.87 \quad .24^{* * *} \quad .37^{* * *} \quad .32$

5. ASI-hostile $\quad 3.44 \quad 0.92 \quad .24^{* * *} \quad .46^{* * *} \quad .44^{* * *}$

6. $\begin{array}{llllll}\text { ASI-benevolent } & 3.53 & 0.95 & .30^{* * *} & .47^{* * *} & .37\end{array}$

$\begin{array}{lllllllllll}\text { 7. } & \text { AMI-hostile } & 3.58 & 1.07 & .18^{*} & .39^{* * *} & .32^{* * *} & .02 & .36^{* * *} & .61^{* * *} & - \\ \text { 8. } & \text { AMI-benevolent } & 3.54 & 1.14 & .31^{* * *} & .50^{* * *} & .40^{* * *} & .41^{* * *} & .62^{* * *} & .80^{* * *} & .57^{* * *}\end{array}$

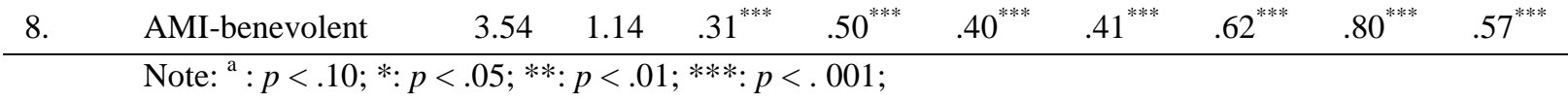
RWA $=$ Right-Wing Authoritarianism; SDO $=$ Social Dominance Orientation; MODSEX $=$ Modern Sexism; ASI = Ambivalent Sexism Inventory; AMI = Ambivalence toward Men Inventory.

Secondly, we conducted regression analyses on each of the five sexism outcomes. The background characteristics (i.e., sex and age) were introduced in step one of the regression, religiosity was entered in step two; and RWA and SDO were introduced in a final step. As shown in Table 2, gender was a relatively weak predictor of the various outcomes. Only for hostile sexism towards women $\left(M_{\text {male }}=3.77, S D_{\text {male }}=1.03\right.$ versus $M_{\text {female }}=3.36, S D_{\text {female }}=$ 0.88) male students scored higher compared to female students. Conversely, female students 
scored higher on hostile sexism towards men $\left(M_{\text {male }}=3.17, S D_{\text {male }}=0.98\right.$ versus $M_{\text {female }}=$ 3.68, $\left.S D_{\text {female }}=1.06\right)$.

Adding religiosity in a second regression step added between 2,2 and 7,5\% explained variance in our sexism outcomes. Importantly, in step three, SDO and especially RWA added a considerably larger proportion of the explained variance (the largest contribution being for hostile sexism towards women). For both measures of hostile sexism (i.e., towards women and towards men), the role of religiosity was even rendered not significant in the final regression step. 
Table 2

Standardized estimates $(\beta S)$ of hierarchical regression analyses on sexist attitudes in Study 1.

\begin{tabular}{|c|c|c|c|c|c|c|c|c|c|c|c|c|c|c|c|}
\hline & \multicolumn{3}{|c|}{ MODSEX } & \multicolumn{3}{|c|}{ ASI-hostile } & \multicolumn{3}{|c|}{ ASI-benevolent } & \multicolumn{3}{|c|}{ AMI-hostile } & \multicolumn{3}{|c|}{ AMI-benevolent } \\
\hline Belgian sample & Step 1 & Step 2 & Step 3 & Step 1 & Step 2 & Step 3 & Step 1 & Step 2 & Step 3 & Step 1 & Step 2 & Step 3 & Step 1 & Step 2 & Step 3 \\
\hline Sex $(1=$ Male $)$ & .09 & .10 & .09 & $.21^{* *}$ & $.22^{* *}$ & $.20^{* * *}$ & .04 & .04 & .03 & $-.17^{*}$ & $-.17^{*}$ & $-.20^{* *}$ & -.01 & .00 & -.03 \\
\hline Age & $-.13^{\mathrm{a}}$ & -.09 & -.05 & $-.23^{* *}$ & $-.19^{* *}$ & $-.14^{*}$ & $-.21^{* *}$ & $-.17^{*}$ & $.12^{\mathrm{a}}$ & $-.16^{*}$ & $-.14^{*}$ & -.10 & $-.25^{* * *}$ & $-.21^{* *}$ & $-.15^{*}$ \\
\hline Religiosity & & $.23^{* * *}$ & $.14^{*}$ & & $.22^{* * *}$ & $.11^{\mathrm{a}}$ & & $.28^{* * *}$ & $.17^{* *}$ & & $.15^{*}$ & .06 & & $.27^{* * *}$ & $.16^{* *}$ \\
\hline RWA & & & $.27^{* * *}$ & & & $.34^{* * * *}$ & & & $.33^{* * *}$ & & & $.23^{* *}$ & & & $.33^{* * * *}$ \\
\hline SDO & & & $.15^{*}$ & & & $.22^{* * *}$ & & & $.19^{* *}$ & & & $.24^{* * *}$ & & & $.23^{* * *}$ \\
\hline$R^{2}$ change & $2,1 \%$ & $5,1 \%{ }^{* * *}$ & $12,4 \%$ *** & $8,2 \%{ }^{* * *}$ & $4,8 \%{ }^{* * *}$ & $21,4 \%$ *** & $4,5 \%{ }^{*}$ & $7,5 \%{ }^{* * *}$ & $18,5 \%$ *** & $6,4 \%{ }^{* *}$ & $2,2 \%^{*}$ & $14,7 \%$ *** & $6,2 \%{ }^{* *}$ & $7,3 \%{ }^{* * *}$ & $20,9 \%{ }^{* * *}$ \\
\hline
\end{tabular}
Note: ${ }^{\mathrm{a}}: p<.10 ; *: p<.05 ; * *: p<.01 ; * * *: p<.001$

MODSEX = Modern Sexism; ASI = Ambivalent Sexism Inventory; AMI = Ambivalence toward Men Inventory; RWA = Right-Wing Authoritarianism; SDO = Social Dominance Orientation. 


\section{Study 2}

Study 2 aimed to broaden the scope of our research in two important ways. Firstly, we wanted to extend the findings of Study 1 by collecting data among adults in the Netherlands (a country with a similar dominant religious denomination as in Study 1; i.e., Christianity) and in Turkey (a country with a different predominant religion; i.e., Islam). Secondly, we also assessed traditional gender role beliefs, a construct strongly related to sexism.

\section{Method}

\section{Participants}

Our first sample consisted of 116 Turkish adults $\left(62,9 \%\right.$ female; $M_{\text {age }}=26.75$ years, $S D_{\text {age }}=7.62$ ), recruited at a University in Ankara. Due to this sampling procedure, almost all $(97,4 \%)$ respondents had a college or university degree. Self-reported household income showed a fairly normal distribution, with $0,0 \%$ reporting their family income to be far below the average level of the country $6,9 \%$ below, $47,4 \%$ around the average, $44,8 \%$ above average, and $0,9 \%$ reporting that their income was much more than the average country level.

Our second sample was recruited by a master student using snowballing and consisted of 99 Dutch adults $\left(69,7 \%\right.$ female; $\left.M_{\text {age }}=34.33, S D_{\text {age }}=14.73\right)$. One percent of respondents had only completed primary school, $13,1 \%$ had completed secondary school, and $85,9 \%$ had a college or university degree. Four percent assessed their family income to be far below the average level of the country, 7,1\% indicated their income was below average, 51,5\% around the average, 33,3\% above average, and 4,0\% reported that their income was far above the country average.

Our third sample consisted of 522 first-year undergraduate students from a Belgian university who were invited to the lab to complete a survey in return for partial course credit 
$\left(76,2 \%\right.$ female; $\left.M_{\text {age }}=19.13, S D_{\text {age }}=4.11\right)$. Relative household income again showed a fairly normal distribution, with $2,1 \%$ indicating their family income to be far below the country average, $11,7 \%$ below, 49,2\% around the average, 35,6\% above, and 1,3\% far above average. In all samples, all respondents completed the full questionnaire, yielding no missing data.

\section{Measures}

In all samples, the same scales were administered on 7-point Likert scales anchored by 1 ("Totally disagree") to 7 ("Totally agree"). For all measures, a validated Dutch version was available. Some scales (i.e., SDO and GAI) were already validated in Turkish (Göregenli, Karakuş, \& Bierhoff, 2013). Other measures were translated into Turkish by a professional translation agency. The second author, an academic psychologist fluent in English and Turkish, compared the original and translated version to inspect their equivalence. Nonequivalent translations were discussed to arrive at consensual agreement on the final wording (see Chen, Van Assche, Vansteenkiste, Soenens, \& Beyers, 2015 for a similar procedure).

Religiosity. Respondents' religiosity was assessed using the same measure as in Study 1. Cronbach's alpha was $.88, .85$, and .89 in the Turkish, Dutch, and Belgian sample, respectively.

Authoritarianism. The same RWA-scale was administered as in Study 1. Cronbach's alpha was $.72, .85$, and .80 in the Turkish, Dutch, and Belgian sample, respectively.

Social Dominance Orientation. A shortened 7-item version of Pratto and colleagues' (1994) SDO- scale was administered (see e.g., Göregenli et al., 2013). Cronbach’s alpha was $.90, .87$, and .85 in the Turkish, Dutch, and Belgian sample, respectively.

Sexist attitudes. Three scales tapped into negative attitudes towards women and traditional gender role beliefs. Firstly, respondents completed the Glick and Fiske (1996) 22- 
item Ambivalent Sexism Inventory. Cronbach's alpha for the hostile subscale was .83, .89, and .84 in the Turkish, Dutch, and Belgian sample, respectively. Cronbach's alpha for the benevolent subscale was $.81, .77$, and .78 in the Turkish, Dutch, and Belgian sample, respectively.

Secondly, the 21-item Gender Attitude Inventory (Ashmore, Del Boca, \& Bilder, 1995) was administered. This instrument consists of two subscales: acceptance of traditional stereotypes (e.g., "Men are generally more adventurous than women"), and approval of classic division of roles within the family (e.g., "A woman is primarily responsible for the household and the children"). Cronbach's alpha was $.87, .90$, and .89 in the Turkish, Dutch, and Belgian sample, respectively.

Thirdly, the 10-item Sex Role Egalitarianism Scale (King \& King, 1997) was administered. These items assess negative attitudes towards equality between men and women across different life domains (e.g., marriage, upbringing, and education). An example item reads "The choice of education is less important for women than for men". Cronbach's alpha was $.78, .81$, and .83 in the Turkish, Dutch, and Belgian sample, respectively.

\section{Results}

We first computed means, standard deviations, and correlations among all study variables (see Table 3). As expected, all constructs were positively interrelated. There were two notable exceptions: in the Turkish and Belgian sample, religiosity was not significantly related to SDO, and in the Dutch sample, religiosity was not significantly associated with benevolent sexism towards women. 
Table 3

Correlations among study variables in Study 2.

\begin{tabular}{|c|c|c|c|c|c|c|c|c|c|}
\hline \multicolumn{2}{|c|}{ Measure } & $\mathrm{M}$ & SD & 1 & 2 & 3 & 4 & 5 & 6 \\
\hline \multicolumn{10}{|c|}{ Turkish sample } \\
\hline 1. & Religiosity & 2.72 & 1.60 & - & & & & & \\
\hline 2. & RWA & 3.06 & 0.87 & $.62^{* * * *}$ & - & & & & \\
\hline 3. & SDO & 2.01 & 1.19 & .15 & $.43^{\text {*** }}$ & - & & & \\
\hline 4. & ASI-hostile & 3.09 & 0.99 & $.31^{* *}$ & $.50^{* * * *}$ & $.31^{* *}$ & - & & \\
\hline 5. & ASI-benevolent & 3.39 & 1.12 & $.38^{* * * *}$ & $.55^{* * * *}$ & $.41^{* * *}$ & $.51^{* * * *}$ & - & \\
\hline 6. & GAI & 2.86 & 0.86 & $.40^{* * * *}$ & $.53^{* * * *}$ & $.36^{* * *}$ & $.52^{* * * *}$ & $.67^{* * * *}$ & - \\
\hline 7. & SRES & 1.89 & 0.82 & $.42^{* * * *}$ & $.50^{* * * *}$ & $.21^{*}$ & $.57^{* * *}$ & $.65^{* * *}$ & $.72^{* * *}$ \\
\hline
\end{tabular}

\begin{tabular}{|c|c|c|c|c|c|c|c|c|c|}
\hline \multicolumn{10}{|c|}{ Dutch sample } \\
\hline 1. & Religiosity & 2.51 & 1.40 & - & & & & & \\
\hline 2. & RWA & 2.63 & 0.92 & $.34^{* * * *}$ & - & & & & \\
\hline 3. & SDO & 2.09 & 1.06 & $.23^{*}$ & $.62^{* * *}$ & - & & & \\
\hline 4. & ASI-hostile & 2.86 & 1.16 & $.25^{*}$ & $.60^{* * * *}$ & $.62^{* * * *}$ & - & & \\
\hline 5. & ASI-benevolent & 2.71 & 0.91 & .08 & $.52^{* * *}$ & $.37^{* * * *}$ & $.47^{* * *}$ & - & \\
\hline 6. & GAI & 2.61 & 0.84 & $.28^{* *}$ & $.66^{* * *}$ & $.51^{* * * *}$ & $.72^{* * * *}$ & $.66^{* * * *}$ & - \\
\hline 7. & SRES & 1.67 & 0.69 & $.38^{* * *}$ & $.62^{* * *}$ & $.46^{* * * *}$ & $.63^{* * *}$ & $.66^{* * *}$ & $.75^{* * *}$ \\
\hline
\end{tabular}

Belgian sample

1. Religiosity $2.43 \quad 1.39 \quad-$

2. RWA $\quad 3.45 \quad 0.89 \quad .11^{*}$

3. SDO $2.51 \quad 1.06 \quad .02 \quad .56^{* * *}$

4. ASI-hostile $\quad 3.26 \quad 0.96 \quad .16^{* * *} \quad .44^{* * *} \quad .49^{* * *}$

5. ASI-benevolent $\quad 3.45 \quad 0.97 \quad .28^{* * *} \quad .51^{* * *} \quad .38^{* * *} \quad .43^{* * *} \quad-$

6. GAI $2.92 \quad 0.79 \quad .28^{* * *} \quad .48^{* * *} \quad .46^{* * *} \quad .57^{* * *} \quad .54^{* * *}$

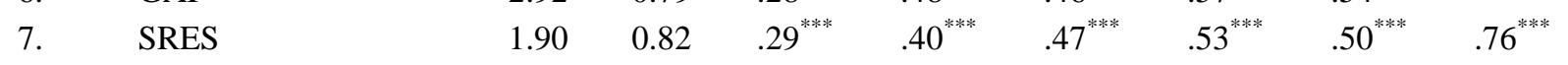

Note: ${ }^{\mathrm{a}}: p<.10 ; *: p<.05 ; * *: p<.01 ; * * *: p<.001$

RWA = Right-Wing Authoritarianism; SDO = Social Dominance Orientation; ASI = Ambivalent

Sexism Inventory; GAI = Gender Attitude Inventory; SRES = Sex Role Egalitarianism Scale.

Secondly, for each sample, we conducted regression analyses on each of the four

sexism outcomes. In a first step, we entered the demographics sex, age, education, and income

as predictors (note that education was a constant in the Belgian student sample). In step two,

religiosity was entered. Finally, in the third step, RWA and SDO were introduced to gain

insight in the relative contribution of these ideological variables in the prediction of sexism. 


\section{Table 4}

Standardized estimates $(\beta s)$ of hierarchical regression analyses on sexist attitudes and gender role beliefs in Study 2.

\begin{tabular}{|c|c|c|c|c|c|c|c|c|c|c|c|c|}
\hline & \multicolumn{3}{|c|}{ ASI-hostile } & \multicolumn{3}{|c|}{ ASI-benevolent } & \multicolumn{3}{|c|}{ GAI } & \multicolumn{3}{|c|}{ SRES } \\
\hline Turkish sample & Step 1 & Step 2 & Step 3 & Step 1 & Step 2 & Step 3 & Step 1 & Step 2 & Step 3 & Step 1 & Step 2 & Step 3 \\
\hline $\operatorname{Sex}(1=$ Male $)$ & $.22^{*}$ & $.26^{*}$ & $.23^{*}$ & .11 & .15 & .09 & -.10 & -.06 & -.11 & .13 & $.17^{\mathrm{a}}$ & .15 \\
\hline Age & .02 & -.01 & -.07 & $.27^{*}$ & $.24^{*}$ & $.20^{*}$ & $.26^{*}$ & $.22^{*}$ & $.19^{\mathrm{a}}$ & $.26^{*}$ & $.22^{*}$ & .18 \\
\hline Education & .00 & .05 & .04 & -.09 & -.04 & -.05 & -.02 & .04 & .03 & .06 & .13 & .12 \\
\hline Income & -.05 & -.07 & -.06 & .03 & .01 & .09 & -.03 & -.05 & .01 & .09 & .07 & .08 \\
\hline Religiosity & & $.34^{* * *}$ & .05 & & $.37^{* * *}$ & .13 & & $.39^{* * *}$ & .17 & & $.44^{* * * *}$ & $.25^{*}$ \\
\hline RWA & & & $.45^{* * *}$ & & & $.31^{* *}$ & & & $.30^{* *}$ & & & $.29^{* *}$ \\
\hline SDO & & & .06 & & & $.26^{* *}$ & & & $.22^{*}$ & & & .05 \\
\hline$R^{2}$ change & $5,4 \%$ & $11,3 \%^{* * *}$ & $14,0 \%{ }^{* * *}$ & $11,8 \%{ }^{*}$ & $13,8 \%$ *** & $16,9 \%{ }^{* * *}$ & $5,7 \%$ & $14,7 \%$ *** & $14,0 \%{ }^{* * *}$ & $12,5 \%$ * & $18,5 \%^{* * *}$ & $5,9 \%{ }^{*}$ \\
\hline Dutch sample & Step 1 & Step 2 & Step 3 & Step 1 & Step 2 & Step 3 & Step 1 & Step 2 & Step 3 & Step 1 & Step 2 & Step 3 \\
\hline Sex $(1=$ Male $)$ & $.30^{* *}$ & $.31^{* * * *}$ & $.23^{* *}$ & $.20^{\mathrm{a}}$ & $.20^{\mathrm{a}}$ & $.19^{\mathrm{a}}$ & .09 & .10 & .06 & $.18^{\mathrm{a}}$ & $.20^{*}$ & $.17^{*}$ \\
\hline Age & $.21^{*}$ & .16 & $.15^{\mathrm{a}}$ & .07 & .05 & .01 & $.25^{*}$ & .17 & .14 & $.23^{*}$ & .11 & .07 \\
\hline Education & $-.26^{*}$ & $-.24^{*}$ & $-.15^{\mathrm{a}}$ & -.03 & -.03 & .06 & -.13 & -.10 & .00 & $-.20^{\mathrm{a}}$ & -.16 & -.07 \\
\hline Income & .10 & .10 & $.14^{\mathrm{a}}$ & -.05 & -.05 & -.02 & .02 & .03 & .07 & .02 & .04 & .07 \\
\hline Religiosity & & .13 & -.03 & & .05 & -.09 & & .18 & .01 & & $.29^{*}$ & .15 \\
\hline RWA & & & $.33^{* * *}$ & & & $.54^{* * *}$ & & & $.54^{* * *}$ & & & $.49^{* * *}$ \\
\hline SDO & & & $.36^{* * * *}$ & & & .03 & & & .15 & & & .08 \\
\hline$R^{2}$ change & $24,1 \%^{* * *}$ & $1,2 \%$ & $32,2 \%$ *** & $5,4 \%$ & $0,2 \%$ & $26,3 \%^{* * *}$ & $10,5 \% *$ & $2,4 \%{ }^{*}$ & $34,9 \%{ }^{* * *}$ & $15,7 \%{ }^{* *}$ & $6,4 \% *$ & $24,9 \%^{* * *}$ \\
\hline Belgian sample & Step 1 & Step 2 & Step 3 & Step 1 & Step 2 & Step 3 & Step 1 & Step 2 & Step 3 & Step 1 & Step 2 & Step 3 \\
\hline Sex $(1=$ Male $)$ & $.27^{* * * *}$ & $.26^{* * * *}$ & $.20^{* * * *}$ & .07 & .05 & .01 & $.22^{* * * *}$ & $.20^{* * * *}$ & $.14^{* * * *}$ & $.35^{* * * *}$ & $.33^{* * *}$ & $.27^{* * *}$ \\
\hline Age & $-.12^{* *}$ & $-.14^{* *}$ & -.04 & -.03 & -.06 & .05 & $-.10^{*}$ & $-.13^{* *}$ & -.04 & $-.08^{*}$ & $-.11^{* *}$ & -.03 \\
\hline Income & -.03 & -.02 & -.04 & -.03 & -.01 & -.04 & .00 & .02 & .00 & .00 & .03 & .01 \\
\hline Religiosity & & $.15^{* * *}$ & $.11^{* *}$ & & $.28^{* * *}$ & $.22^{* * *}$ & & $.28^{* * *}$ & $.24^{* * *}$ & & $.27^{* * *}$ & $.24^{* * *}$ \\
\hline RWA & & & $.23^{* * *}$ & & & $.42^{* * * *}$ & & & $.29^{* * *}$ & & & $.17^{* * *}$ \\
\hline SDO & & & $.32^{* * *}$ & & & $.15^{* *}$ & & & $.26^{* * *}$ & & & $.32^{* * *}$ \\
\hline$R^{2}$ change & $8,8 \%^{* * *}$ & $2,3 \%{ }^{* * *}$ & $22,6 \%{ }^{* * *}$ & $0,6 \%$ & $7,5 \%{ }^{* * *}$ & $24,7 \%$ *** & $5,7 \%{ }^{* * *}$ & $7,8 \%{ }^{* * *}$ & $22,4 \%$ *** & $12,8 \%$ *** & $7,2 \%{ }^{* * *}$ & $18,3 \%^{* * *}$ \\
\hline
\end{tabular}


Note: ${ }^{\mathrm{a}}: p<.10 ; *: p<.05 ; * *: p<.01 ; * * *: p<.001$;

SRES = Sex Role Egalitarianism Scale; ASI = Ambivalent Sexism Inventory; GAI = Gender Attitude Inventory; RWA = Right-Wing Authoritarianism; SDO =

Social Dominance Orientation. 
The results, reported in Table 4, showed that in the Turkish and Dutch adult samples, gender was a relatively weak predictor of the various forms of sexism and gender role beliefs. In the Belgian student sample, men showed significantly higher scores on hostile sexism and traditional gender role beliefs than women did.

In a second regression step, religiosity was a significant predictor of all outcomes in the Turkish and Belgian sample. In the Dutch sample, however, one's level of religiosity contributed little above and beyond the background characteristics. In a third step, entering SDO and particularly RWA did add considerably to the explained variance. It seems that, especially when it comes to ambivalent sexism and traditional gender role beliefs, socialideological attitudes play a major role above and beyond religiosity. Importantly, this pattern of result was found in all samples.

\section{Mini-meta-analysis}

Across four samples (total $N=964$ ), we considered the role of religiosity and social attitudes in the prediction of sexist attitudes. We now calculated the overall meta-analytic effect sizes of our key predictors. In particular, we tested a random effects model using the Open Psychometric Meta-analysis software (Version 1.0b9) by Wiernik (2017). We corrected for statistical artifacts using the artifact distribution method and freely estimated the true residual variance $\left(\mathrm{SD}_{\text {res }}\right)$. Firstly, we calculated the weighted associations based on the simple bivariate correlations between our predictors and our outcomes. Secondly, and most relevant to our research question, we calculated the meta-analytic effect size of each predictor on all outcomes, while simultaneously controlling for the impact of the other two predictors (i.e., relying on their partial correlations). Table 5 portrays all effect sizes with their observed and true standard deviations, their confidence intervals, and their credibility intervals (which represent a range of values that includes the true effect size with $80 \%$ probability). 


\section{Table 5}

Meta-analytic effect size estimates of religiosity, RWA, SDO with sexist attitudes, based on bivariate (left panel) and partial (right panel) correlations.

\begin{tabular}{lccccc|ccccc}
\hline Predictor & $r$ & $\mathrm{SD}_{\mathrm{r}}$ & $\mathrm{SD}_{\text {res }}$ & $\begin{array}{c}95 \% \\
\text { Conf. Int. }\end{array}$ & $\begin{array}{c}80 \% \\
\text { Cred. Int. }\end{array}$ & $r$ & $\mathrm{SD}_{\mathrm{r}}$ & $\mathrm{SD}_{\text {res }}$ & $\begin{array}{c}95 \% \\
\text { Conf. Int. }\end{array}$ & $\begin{array}{c}80 \% \\
\text { Cred. Int. }\end{array}$ \\
\hline Religiosity & .27 & .07 & .04 & {$[.24 ; .30]$} & {$[.22 ; .31]$} & .19 & .09 & .07 & {$[.15 ; .23]$} & {$[.10 ; .28]$} \\
RWA & .47 & .06 & .04 & {$[.44 ; .49]$} & {$[.42 ; .52]$} & .29 & .08 & .06 & {$[.25 ; .33]$} & {$[.22 ; .36]$} \\
SDO & .42 & .07 & .05 & {$[.39 ; .45]$} & {$[.35 ; .48]$} & .24 & .09 & .07 & {$[.20 ; .28]$} & {$[.15 ; .32]$} \\
\hline
\end{tabular}

Note: $r=$ mean uncorrected effect size; $\mathrm{SDr}=$ observed standard deviation of the effect size; SDres= true residual variance; Conf. Int. = confidence interval; Cred. Int. = credibility interval;

RWA $=$ Right-Wing Authoritarianism; SDO = Social Dominance Orientation.

Overall, the effect sizes of RWA and SDO on sexism seem to be considerably larger compared to the effect size of religiosity. It should be noted, however, that the confidence intervals around the meta-analytic effect sizes based on the partial correlations show some overlap. In particular, when controlling for one another, the effect sizes of religiosity and SDO did not substantially differ in terms of their relative contribution in predicting sexism, as did the effect sizes of SDO and RWA. Importantly, even when taken into account their shared variance, RWA still significantly outweighed religiosity.

\section{Discussion}

In the present research, we aimed to advance our understanding of the psychological foundations of sexism and traditional gender role beliefs. Based on adult and student samples from three different countries (i.e., Turkey, the Netherlands, and Belgium) with a different religious and cultural makeup, two studies and an internal meta-analysis allow us to draw three conclusions. The first conclusion pertains to the rather limited impact of the respondents' gender in explaining a range of sexist attitudes. This remarkably restricted influence also emerged in the studies by Glick and colleagues (2004), and Roets, Van Hiel, and Dhont (2012). Gender group affiliations thus seem to play only a minor role in predicting sexism. Instead, individual differences in religiosity and social attitudes were demonstrated to explain a substantial portion of the variance in sexism towards both the own and the other gender in all samples of the present studies. 
Our second conclusion refers to the relatively moderate unique contribution of religiosity in predicting sexism and traditional gender role beliefs. At first glance, a higher level of religiosity was associated with higher sexism. These findings parallel the results of previous studies with Christian (e.g., Glick, Lameiras, \& Castro 2002), Muslim (Taşdemir \& Sakall1-Uğurlu, 2010) and Jewish (Gaunt, 2012) samples. Nevertheless, when social attitudes were taken into account, the contribution of religiosity dropped markedly (see also Hellmer et al., 2018).

The third and most important conclusion thus concerns the essential influence of the socio-ideological attitude dimensions on sexism. Allport (1954) already asserted that "a person's prejudice is unlikely to be merely a specific attitude to a specific group; it is more likely to be a reflection of his whole habit of thinking about the world" (p. 170). Indeed, when looking at various facets of sexism and traditional gender role beliefs, one's social-ideological attitudes appear to matter above and beyond one's gender group or the depth of one's religious commitment. As such, the present results corroborated the assertions of Sibley and colleagues (2007) and Roets and colleagues (2012) that RWA and SDO are the primary individual difference antecedents of sexism towards both women and men (see also Bosson, Vandello, \& Buckner, 2018, for an excellent overview).

People holding sexist and traditional role-based attitudes seem to be characterized by RWA-based motivations of social order as well as by SDO-based motivations of group competitiveness, rather than by primarily religious motivations. Overall, our mini-metaanalysis revealed that the relative contributions of SDO and especially RWA outweighed the role of religiosity. As such, it can be concluded that people higher in sexism and traditional role beliefs tend to display higher levels of religiosity, but also higher levels of SDO, and particularly higher RWA-levels. 
Importantly, our findings provide support for this general claim a) in various religious contexts, b) for various types of sexist attitudes and traditional gender role beliefs, and c) regardless of the gender of both actor and target. Indeed, for both men and women, RWA, (and to a certain extent SDO and religiosity) showed unique predictive value in explaining sexism toward women as well as toward men, and in explaining traditional gender role attitudes. Corroborating the findings of Hellmer and colleagues (2018) in the Swedish context, the most crucial conclusion here is that - overall - authoritarianism appears to be the most potent and robust predictor across outcomes and across samples. Following the DualProcess Model (Duckitt, 2001), it can be argued that people (both male and female) high in RWA would urge for stability, cohesion, and the preservation of traditional gender roles for members of both sexes. Individuals high in SDO, on the other hand, might strongly adhere to the "natural" inequality where men are higher than women on the social-hierarchical ladder. Among women, this worldview might seem undesirable or even in conflict with their own group's interest. Nonetheless, studies within System Justification Theory (Jost \& Banaji, 1994) have repeatedly shown that members of underprivileged groups often endorse their unfavorable position in favor of the status quo (see also Roets et al., 2012).

Furthermore, by studying these issues in societies with a different predominant religious denomination, and by assessing a broad range of gender-related attitudes (i.e., attitudes towards egalitarian sex roles, traditional gender stereotypes, subtle sexism, and hostile and benevolent forms of sexism towards both women and men), we were also able to have some evidence for the generalizability of our findings. In general, we found very similar results in all samples regarding all outcomes. Interestingly, while we did not replicate the divergence often found in previous studies where RWA was uniquely associated with benevolent and SDO uniquely with hostile sexism (Begany \& Milburn, 2002; Christopher \& Mull, 2006; Sibley et al., 2007), our results seem to suggest that religiosity is primarily related 
to benevolent forms of sexism (see also Hellmer et al., 2018). Indeed, religiosity seems more intertwined with beliefs that women need to be protected by men than with beliefs that women are incompetent and inferior to men.

It should be noted that we tapped into religiosity using a rather broad and general measure, whereas religiosity can also be seen as a multifaceted construct composed of several components (e.g., frequency of prayers and attendance of religious services, spirituality, fundamentalism, and intrinsic, extrinsic, and quest orientations). The meta-analysis of Whitley (2009) already revealed that some components may have opposing associations with prejudices. For example, while higher intrinsic religious orientation was related to more negative attitudes towards gays and lesbians, extrinsic orientation showed no relationship to these attitudes, and higher quest orientation was even related to more positive attitudes. Hence, future studies could examine whether beyond the overall association with religiosity as a general construct, behavioral, functional, denominational, and structural components of religiosity all relate to gender-related attitudes in the same way, or whether there are subtle differences at the facet level.

In the same vein, RWA and SDO to some degree represent multifaceted constructs. Specifically, authoritarianism can be seen as a conglomerate of conventionalism, submission, and aggression, while SDO can be segmented into a "group-based dominance" and an “opposition to equality" factor. However, given that the present research, similar to most previous research, employed RWA and SDO scales intended as broad measures, it cannot provide detailed insights into which specific components are most strongly associated with gender-related attitude. Therefore, future research designs could purposefully test this by selecting scales that tap into subcomponents (e.g., the tripartite approach to RWA as proposed by Duckitt, Bizumic, Krauss \& Heled, 2010). 
Moreover, generalizability claims are obviously limited by our use of two convenience samples (in Turkey and the Netherlands) and two student samples (in Belgium). Additionally, the cross-sectional design of our studies does not allow for causal claims. Random representative samples, ideally followed up over time, would allow for more confident inferences. Such future longitudinal studies with diverse samples and a variety of religions (e.g., also Jewish or Buddhist individuals) would enhance our understanding of the factors that shape sexism even more. A tentative research question could, for instance, focus on the role of various religiosity facets in several contexts simultaneously, and examine whether country-level determinants (e.g., national levels of women's rights) moderate the individuallevel religiosity-sexism association.

In sum, the present research indicated that, in order to understand phenomena ranging from subtle negative (and positive) gender stereotypes to blatant beliefs about the inferiority of a certain sex, we should look beyond group membership (e.g., sex of both actor and target). Indeed, this set of studies provides a broadened framework for sexism and gender-related attitudes, demonstrating that, in various societies, it is warranted to (also) take into account religiosity, but especially individual differences in social-ideological attitudes when considering the individual level sources of sexism. 


\section{References}

Ahmed, S., \& Matthes, J. (2017). Media representation of Muslims and Islam from 2000 to 2015: A meta-analysis. International Communication Gazette, 79(3), 219-244.

Allport, G. (1954). The Nature of Prejudice. Reading, MA: Addison-Wesley.

Allport, G. W., \& Ross, J. M. (1967). Personal religious orientation and prejudice. Journal of Personality and Social Psychology, 5(4), 432-443.

Altemeyer, B. (1981). Right-wing Authoritarianism. Winnipeg: University of Manitoba Press.

Anderson, J., \& Koc, Y. (2015). Exploring patterns of explicit and implicit anti-gay attitudes in Muslims and Atheists. European Journal of Social Psychology, 45(6), 687-701.

Ashmore, R. D., Del Boca, F. K., \& Bilder, S. M., (1995). Construction and validation of the gender attitude inventory, a structured inventory to assess multiple dimensions of gender attitudes. Sex Roles, 32(11-12), 753-785.

Begany, J. J., \& Milburn, M. A. (2002). Psychological predictors of sexual harassment: Authoritarianism, hostile sexism, and rape myths. Psychology of Men \& Masculinity, 3(2), 119.

Bosson, J. K., Vandello, J. A., \& Buckner, C. E. (2018). The Psychology of Sex and Gender. SAGE Publications.

Chen, B., Van Assche, J., Vansteenkiste, M., Soenens, B., \& Beyers, W. (2015). Does psychological need satisfaction matter when environmental or financial safety are at risk?. Journal of Happiness Studies, 16, 745-766.

Christopher, A. N., \& Mull, M. S. (2006). Conservative ideology and ambivalent sexism. Psychology of Women Quarterly, 30(2), 223-230. 
Duckitt, J. (2001). A dual-process cognitive-motivational theory of ideology and prejudice. In M. P. Zanna (Ed.), Advances in Experimental Social Psychology (Vol. 33, pp. 41-113). New York: Academic Press.

Duckitt, J., Bizumic, B., Krauss, S. W., \& Heled, E. (2010). A tripartite approach to rightwing authoritarianism: The authoritarianism-conservatism-traditionalism model. Political Psychology, 31(5), 685-715.

Duriez, B., \& Van Hiel, A. (2002). The march of modern fascism. A comparison of social dominance orientation and authoritarianism. Personality and Individual Differences, 32(7), 1199-1213.

Fitzpatrick Bettencourt, K. E., Vacha-Haase, T., \& Byrne, Z. S. (2011). Older and younger adults' attitudes toward feminism: The influence of religiosity, political orientation, gender, education, and family. Sex Roles, 64, 863-874

Fleischmann, F., (2010). Integratie en religiositeit onder de Turkse tweede generatie in Berlijn en Amsterdam. Migrantenstudies, 2, 199-219.

Gaunt, R. (2012). "Blessed is he who has not made me a woman": Ambivalent sexism and Jewish religiosity. Sex Roles, 67(9-10), 477-487.

Göregenli, G, Karakuş, P., \& Bierhoff, H.W., (2013). The values and attitudes towards TEU in a cross-cultural sample. Psychology Research, 2(6), 343-360.

Glick, P., \& Fiske, S. T., (1996). The ambivalent sexism inventory: Differentiating hostile and benevolent sexism. Journal of Personality and Social Psychology, 70(3), 491-512. 
Glick, P., \& Fiske, S. T. (1999). The ambivalence toward men inventory: Differentiating between hostile and benevolent beliefs about men. Psychology of Women Quarterly, $23,519-536$.

Glick, P., Fiske, S. T., Mladinic, A., Saiz, J., Abrams, D., Masser, B., Adetoun, B., Osagie, J. E., Akande, A., Alao, A., Brunner, A., Willemsen, T. M., Chipeta, K., Dardenne, B., Dijksterhuis, A., Wigboldus, D., Eckes, T., Six-Materna, I., Expósito, F., Moya, M., Foddy, M., Kim, H-J., Lameiras, M., Sotelo, M. J., Mucchi-Faina, A., Romani, M., Sakallı, N., Udegbe, B., Yamamoto, M., Ui, M., Ferreira, M. C., \& López, W. L. (2000). Beyond prejudice as simple antipathy: hostile and benevolent sexism across cultures. Journal of Personality and Social Psychology, 79, 763-775.

Glick, P., Lameiras, M., \& Castro, Y. R. (2002). Education and Catholic religiosity as predictors of hostile and benevolent sexism toward women and men. Sex Roles, 47(9$10), 433-441$.

Glick, P., Lameiras, M., Fiske, S. T., Eckes, T., Masser, B., Volpato, C., Manganelli, A. M., Pek, J. C., Huang, L., Sakallı-Uğurlu, N., Castro, Y. R., Pereira, M. L. D., Willemsen, T. M., Brunner, A., Materna, I. S., \& Wells, R. (2004). Bad but bold: Ambivalent attitudes toward men predict gender inequality in 16 nations. Journal of Personality and Social Psychology, 86(5), 713.

Hellmer, K., Stenson, J. T., \& Jylhä, K. M. (2018). What's (not) underpinning ambivalent sexism?: Revisiting the roles of ideology, religiosity, personality, demographics, and men's facial hair in explaining hostile and benevolent sexism. Personality and Individual Differences, 122, 29-37.

Jost, J. T., \& Banaji, M. R. (1994). The role of stereotyping in system-justification and the production of false consciousness. British Journal of Social Psychology, 33(1), 1-27. 
King, L. A., \& King, D.W., (1997). Sex-role egalitarianism scale. Psychology of Women Quarterly, 21(1), 71-87.

Meloen, J. D. (1991). Inventarisatie Nederlandse F-schalen 1959-1990. Intolerant en onderdanig, 186-222.

Mikołajczak, M., \& Pietrzak, J. (2014). Ambivalent sexism and religion: Connected through values. Sex roles, 70(9-10), 387-399.

Pratto, E, Sidanius, J., Stallworth, L. \& Malle, B. (1994). Social dominance orientation: A personality variable predicting social and political attitudes. Journal of Personality and Social Psychology, 67(4), 741-763.

Roets, A., Van Hiel, A., \& Dhont, K. (2012). Is sexism a gender issue? A motivated social cognition perspective on men's and women's sexist attitudes toward own and other gender. European Journal of Personality, 26(3), 350-359.

Ruether, R. (1998). Religion and sexism: Images of women in the Jewish and Christian traditions. Wipf and Stock Publishers.

Seguino, S. (2011). Help or hindrance? Religion's impact on gender inequality in attitudes and outcomes. World Development, 39(8), 1308-1321.

Sibley, C. G., Robertson, A., \& Wilson, M. S. (2006). Social dominance orientation and rightwing authoritarianism: Additive and interactive effects. Political Psychology, 27(5), $755-768$.

Sibley, C. G., Wilson, M. S., \& Duckitt, J. (2007). Antecedents of men's hostile and benevolent sexism: The dual roles of social dominance orientation and right-wing authoritarianism. Personality and Social Psychology Bulletin, 33(2), 160-172. 
Swim, J. K., Aikin, K. J., Hall, W. S., \& Hunter, B. A. (1995). Sexism and racism: Oldfashioned and modern prejudices. Journal of Personality and Social Psychology, 68(2), 199-214.

Taşdemir, N., \& Sakallı-Uğurlu, N. (2010). The relationships between ambivalent sexism and religiosity among Turkish university students. Sex Roles, 62(7-8), 420-426.

Van Assche, J., Bostyn, D. H., De keersmaecker, J., Dardenne, B., \& Hansenne, M. (2017). Intergroup reconciliation between Flemings and Walloons: The predictive value of cognitive style, authoritarian ideology, and intergroup emotions. Psychologica Belgica, 57(3), 132-155.

Van Assche, J., Roets, A., De keersmaecker, J. \& Van Hiel, A. (2017). The mobilizing effect of right-wing ideological climates: Cross-level interaction effects on different types of outgroup attitudes. Political Psychology, 38(5), 757-776.

Van Hiel, A., Van Assche, J., De Cremer, D., Onraet, E., Bostyn, D., Haesevoets, T., \& Roets, A. (2018). Can education change the world? Education amplifies differences in liberalization values and innovation between developed and developing countries. Plos One, 13(6), e0199560.

Wiernik, B. M. (2017) Open Psychometric Meta-analysis [Computer software]. Version 1.0b9. Retrieved from https://github.com/bwiernik/OPMA-Excel.

Whitley Jr, B. E. (2009). Religiosity and attitudes toward lesbians and gay men: A metaanalysis. International Journal for the Psychology of Religion, 19(1), 21-38. 